\title{
The COST example for outreach to the general public: I love my Sun
}

\author{
Yurdanur Tulunay ${ }^{1, *}$, Norma Bock Crosby ${ }^{2}$, Ersin Tulunay $^{3}$, Stijn Calders ${ }^{2}$, Aleksei Parnowski ${ }^{4}$, and Desanka Sulic ${ }^{5}$ \\ 1 Department of Aerospace Engineering, METU, Ankara, Turkey \\ *corresponding author: e-mail: ytulunay@ae.metu.edu.tr \\ 2 Belgian Institute for Space Aeronomy, Ringlaan-3-Avenue Circulaire, 1180 Brussels, Belgium \\ 3 Department of Electrical and Electronics Engineering, METU, Ankara, Turkey \\ 4 Space Research Institute NASU \& NSAU, Kyiv, Ukraine \\ 5 Faculty of Ecology and Environmental Protection, University Union - NIKOLA TESLA, Belgrade, Serbia
}

Received 7 June 2012 / Accepted 9 January 2013

\begin{abstract}
It is important to educate children about the important role that the Sun has in their lives. This paper presents an educational outreach tool entitled "I Love My Sun" that has been developed for school children in the approximate age range of 7 through 11 years. The main objective of this tool is to make children aware of space weather, the Sun, Sun-Earth relations and how they, the children, are part of this global picture. Children are given a lecture about the Sun. The lecture is preceded and followed by the children drawing a picture of the Sun. In this paper the background behind the "I Love My Sun" initiative is given and it is described how to perform an "I Love My Sun". The main results from events in Turkey, Belgium, Ukraine and Serbia are presented.
\end{abstract}

Key words. space weather - outreach - education - space environment - Sun

\section{Introduction}

Our closest star, the Sun, provides us with life as we know it here on Earth. It is studied in detail by scientists, so that a better understanding of its role in the changing weather of Earth may be obtained as well as how it influences the space environment - better known as "space weather". Modern society has become dependent on space technology and human activities in space are increasing at a rapid rate. However, our space systems are more than ever vulnerable to space weather due to developments in technology such as miniaturisation. Therefore, there is a vital need for providing education and outreach activities at all levels in the space weather field, as well as space physics in general.

To create awareness among children that they are part of the global Sun-Earth scenario, the Sun can be used as an innovative teaching tool. Indeed, it is important that children, the flag carriers of tomorrow, become aware about the dynamic relation that exists between the Sun and Earth. In their Table 1 (item 2) Adams \& Slater (2000) list one of the major astronomy objectives for K-4 students ( $\mathrm{K}=$ kindergarten): "the Sun provides the light and heat necessary to maintain the temperature of Earth". In the same table, it is stated that "Rollins et al. (1983) found only 59\% of high school seniors related Sun's energy to higher order concepts and principles as major source of energy powering Earth's phenomena".

It is therefore essential that children are exposed to topics such as the Sun and related phenomena while they are still young no matter how elementary the level of relevant information conveyed to them is. NASA's Education and Public Outreach lesson plans for $\mathrm{K}-5,6-8,9-12$ stress this in a compact and concise manner "NASA's collection of lesson plans and "easy to do" activities are just the hook you need to bring the science of space weather to your students. Here you can do everything from building an edible model of the Sun to learning how to make a real space weather broadcast!" [1].

In Yair et al. (2001) a virtual dynamic 3-D model of the Solar System, in which the student journeys through it as the virtual world continues to behave and operate in its usual manner, is presented. The platform helps to overcome the inherent geocentric view and ensures the transition to a scientific, heliocentric view of the Solar System. Recently, Meyer et al. (2011) present the Lunar Phases Project, an ongoing effort utilising students' actual observations within a mental model building framework to improve student understanding of the causes and process of the lunar phases. Examples such as these are unique and inspirational educational methods for knowledge transfer in schools.

International educational initiatives include the EU Universe Awareness (EU-UNAWE) project that uses the beauty and grandeur of the Universe to inspire and educate young children (4-10 years old) as well as encourage them to develop an interest in science and technology [2]. The International Heliophysical Year (IHY) in 2007 was sponsored by the United Nations on the 50th anniversary of the space age and driven by international collaborative programmes. The "Outreach and Education" programme was one of the four main IHY components (Thompson et al. 2009; [3]). The EU FP6 "Space Weather and Europe - an Educational Tool with the Sun (SWEETS)" project was a public outreach activity and encompassed some of the activities of IHY. Both SWEETS and the EU COST 724 Action "Developing the Scientific Basis for Monitoring, Modelling and Predicting Space Weather" initiated scientific collaboration between universities, governmental and industrial bodies in Europe towards education and public outreach in space weather related topics. The target was social groups of all ages, professions and occupations [4]. 
Table 1. Metric template used for the relative comparison of the two BÜ Özel Ayşeabla school visits of the "before" and "after" drawings of the second visit; $\mathrm{B}=$ before, $\mathrm{A}=$ after, and $\mathrm{i}=$ item number.

\begin{tabular}{|c|c|c|c|c|}
\hline \multicolumn{5}{|c|}{ Evaluation of the drawings BEFORE(B) the lecture } \\
\hline $\mathrm{Bi}$ & Human features are used as solar features & Yes & No & \\
\hline Bii & $\begin{array}{l}\text { Sun-Earth connections are in the form of daily life experiences } \\
\text { (e.g., Flowers, grass, happy children, etc.) }\end{array}$ & Yes & No & \\
\hline Biii & $\begin{array}{l}\text { Is the Sun a major character in the drawing (e.g., does the } \\
\text { Sun occupy a major part or is it placed in one of the } \\
\text { corners of the drawing?) }\end{array}$ & Yes & No & \\
\hline Biv & $\begin{array}{l}\text { The difference between age } 8 \text { and age } 11 \text { in quality } \\
\text { of perception, enhancement of knowledge and expression }\end{array}$ & 0 (No diff.) & $+($ Increased $)$ & $-($ Decreased $)$ \\
\hline \multicolumn{5}{|c|}{ Evaluation of the drawings AFTER(A) the lecture } \\
\hline $\mathrm{Ai}$ & Human features are replaced by & $\begin{array}{l}\text { Space Weather (Sun Spots; } \\
\text { Solar Wind; Aurora; ... .) }\end{array}$ & & \\
\hline Aii & Sun-Earth relations are expressed in terms of & $\begin{array}{l}\text { Space Weather (Sun } \\
\text { Spots; Solar Wind; } \\
\text { Aurora; ...) }\end{array}$ & & \\
\hline Aiii & Has the Sun become a major character? & Yes & No & \\
\hline Aiv & $\begin{array}{l}\text { Does the child use brighter/richer colours in this phase of the } \\
\text { event? }\end{array}$ & Yes & No & Same \\
\hline Av & Does the child draw a similar drawing to that of the pre-tutorial? & Yes & No & \\
\hline Avi & $\begin{array}{l}\text { The difference between age } 8 \text { and age } 11 \text { in quality of perception, } \\
\text { enhancement of knowledge and expression }\end{array}$ & 0 (No diff.) & $+($ Increased $)$ & $-($ Decreased $)$ \\
\hline
\end{tabular}

Specifically, under the umbrella of IHY and the COST 724 Action the "I Love My Sun" concept was created and initiated by Yurdanur Tulunay, Professor at the Middle East Technical University in Turkey. As the first phase "I Love My Sun 1" was conducted in 2007 and 2008. Two schools were chosen for the first event in Ankara representing two different social backgrounds. The children's drawings were exhibited at art galleries and schools. Public media (press, radio, TV) were invited to observe the whole activity. For more information see Tulunay (2009).

The "I Love My Sun" initiative has continued in three phases as a European outreach activity under the umbrella of the COST ES0803 Action [5, 6]. The main objectives of "I Love My Sun 2" were to make children (any type of class and school) aware of space weather, Sun, Sun-Earth relations and of how they, the children, are part of this global picture. Furthermore, it was investigated if this educational tool can lead to novel ways of approaching children with autism spectrum disorder (ASD). Thereafter, "I Love My Sun" went from being a national initiative in Turkey to one which spreads across Europe with the long-term goal of going world-wide. This "spatial dimension" approach is enriching the content and objectives of the original "I Love My Sun" initiative (Thompson et al. 2009). "I Love My Sun 3" events have been conducted in Turkey, Belgium, Ukraine and Serbia. In the last phase a "temporal dimension" was added and a school where the event had been held earlier was re-visited "I Love My Sun 4".

This paper presents a new tool for education and outreach based on the results of the "I Love My Sun" initiative. In Section 2 it is presented how to perform an "I Love My Sun" event. Examples and outcomes of "I Love My Sun" events that have been held under the umbrella of the COST ES0803 Action are presented and discussed in Section 3. The paper ends with a conclusion and an outlook to the future.

\section{2. "I Love My Sun" Events}

The main objective of the "I Love My Sun" initiative is to make children ( $\sim-11$ years old) aware of space weather, the
Sun, Sun-Earth relations and of how they, the children, are part of this global picture. The tool developed for this purpose makes it easier for children to be aware of space weather on a simple/basic level as they are of the weather on Earth. On the "I Love My Sun" website it is described in detail how to organise an "I Love My Sun" event that is comprised of three main parts (1. Prior to school visit, 2. School visit, 3. After school visit; [6]). In the following a short description is given.

Prior to the school visit there should be some communication with the class teacher. This includes gathering information concerning the school (public/private, location of school (city/ rural), does the school specialise in any specific topics (music, science, etc.)?).

At the beginning of the school visit information is gathered regarding each student (name, age, sex $(\mathrm{F} / \mathrm{M})$, has the student already been given a lecture/seen a movie/read a book about the Sun?). Children are then asked to draw the Sun as they perceive it. Thereafter a basic lecture on the Sun-Earth relation and space weather is given to the children. The level of information conveyed should be on a simple level, but sufficient, so that children are aware of the Sun's basic features (e.g., sunspots) and space weather including the formation of the magnetosphere. This includes an analogy between the Sun and the Earth in terms of magnetism, days, seasons, precipitations, storms, etc. The lecture may be followed by a short brainstorming session during which the students are interactive and ask questions. Then the children are asked to draw the Sun again.

Following a school visit each drawing is to be scanned and made into an electronic version. It is advisable that the "School", "Class" and "General Impression" documents be filled in since these documents will complement the relevant database of drawings that is being constructed and may later be used for further analysis [6]. By analysing the "before" and "after" drawings one can obtain information concerning how well the school children understood the contents of the lecture and which part of the lecture had the main influence on the children.

The success of a school visit includes having given the lecture in a way so that the children are able to understand 

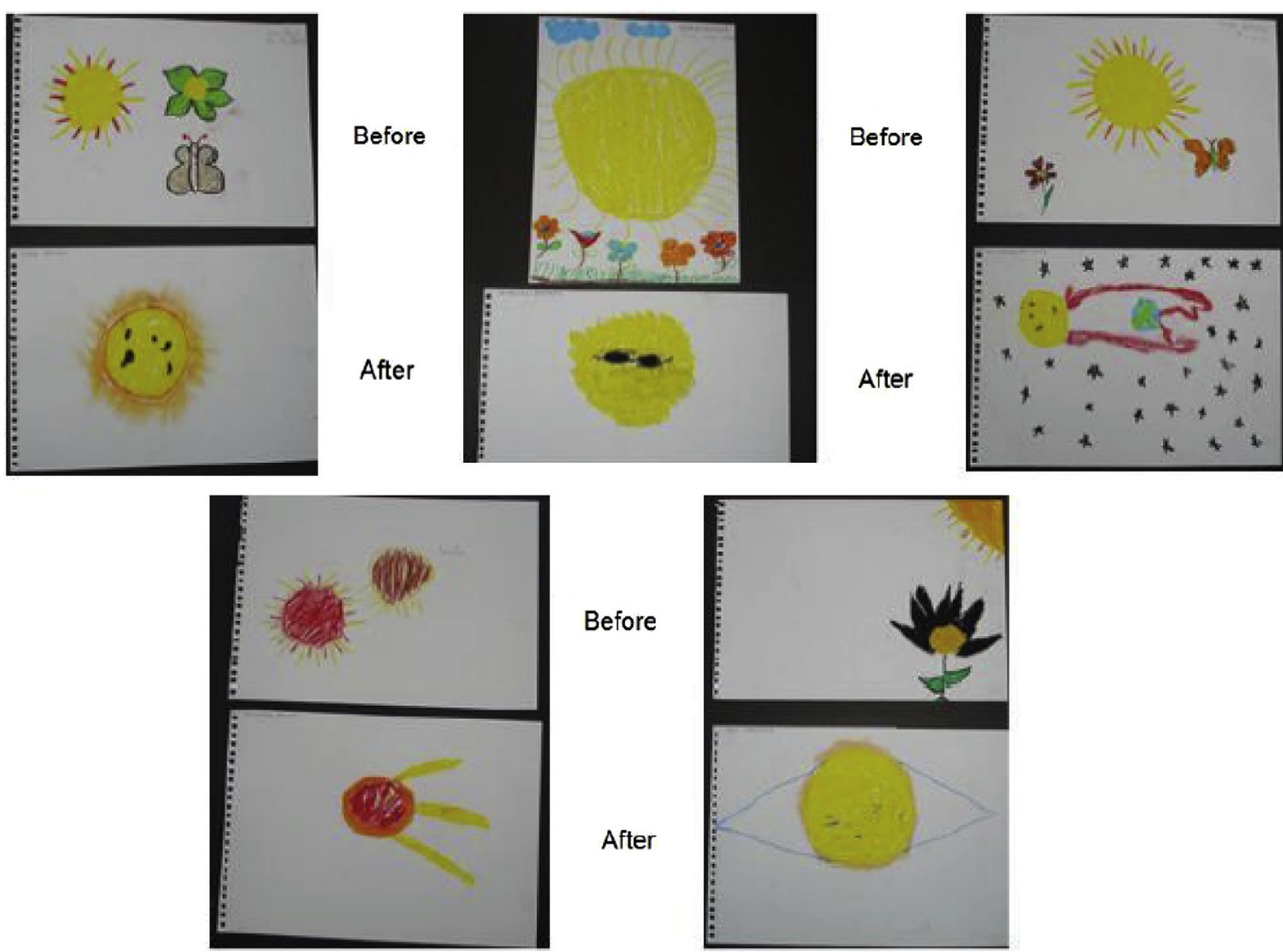

Fig. 1. Some of the "before" and "after" drawings of the Turkish children (without ASD) from the Kütükçü Alibey Illköğretim Okulu primary state school (I Love My Sun 2 event).
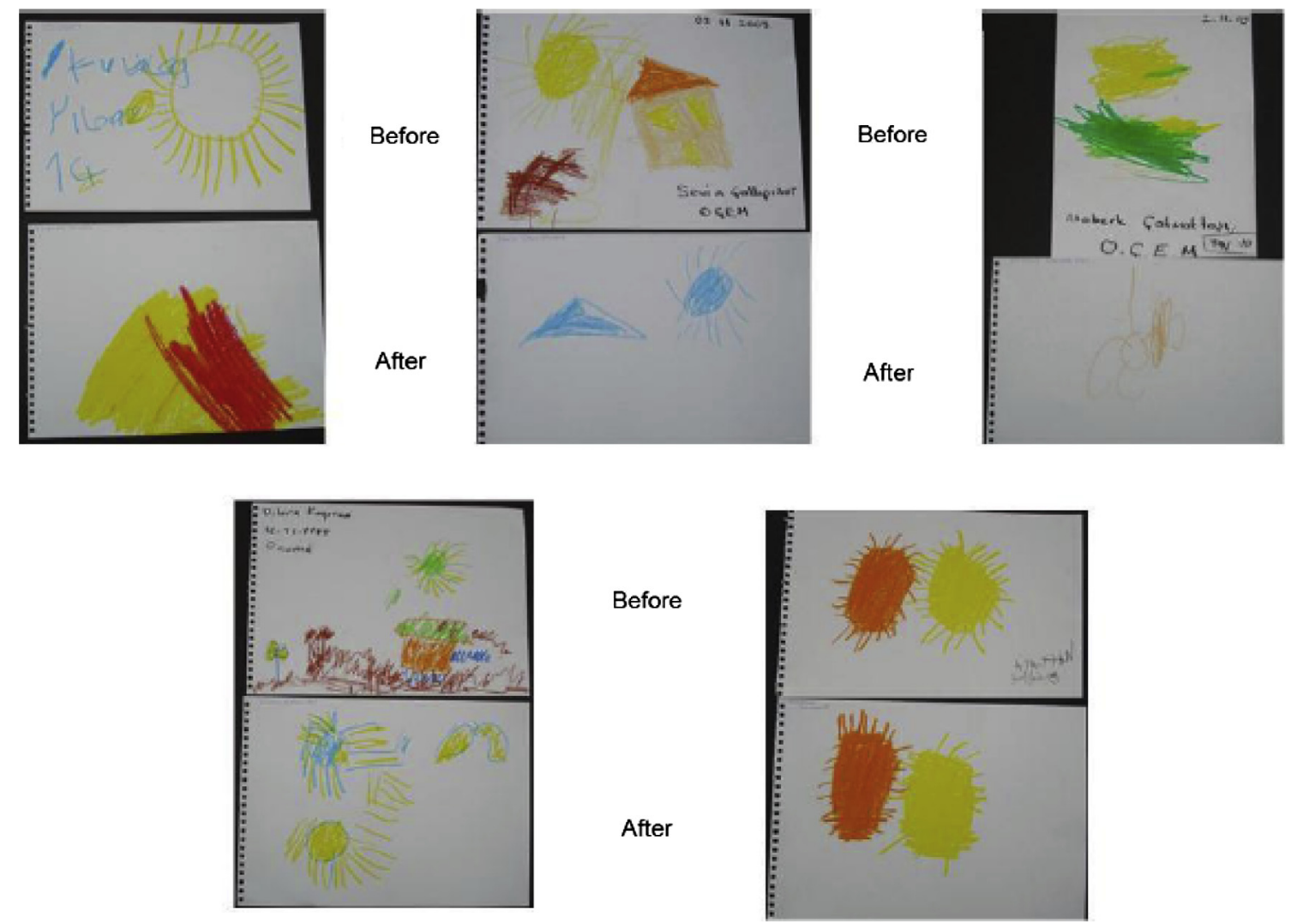

Fig. 2. Some of the "before" and "after" drawings of the Turkish children (with ASD) from the Kütükçü Alibey İlköğretim Okulu primary state school (I Love My Sun 2 event). 

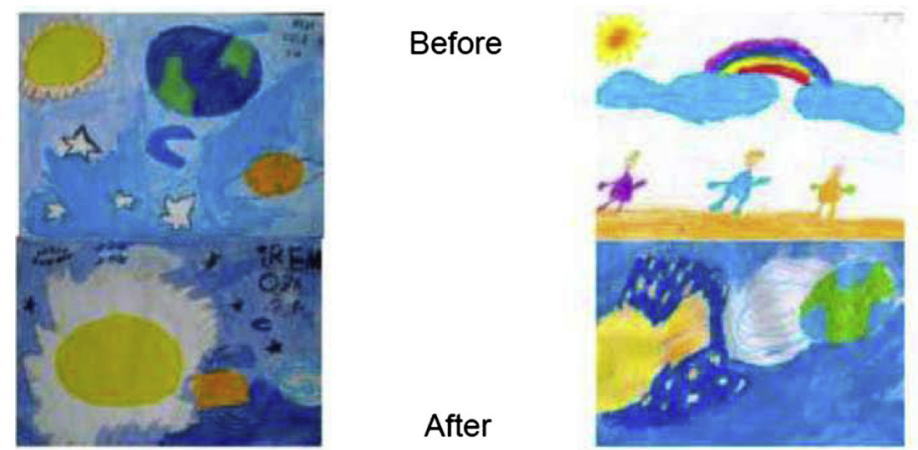

Before
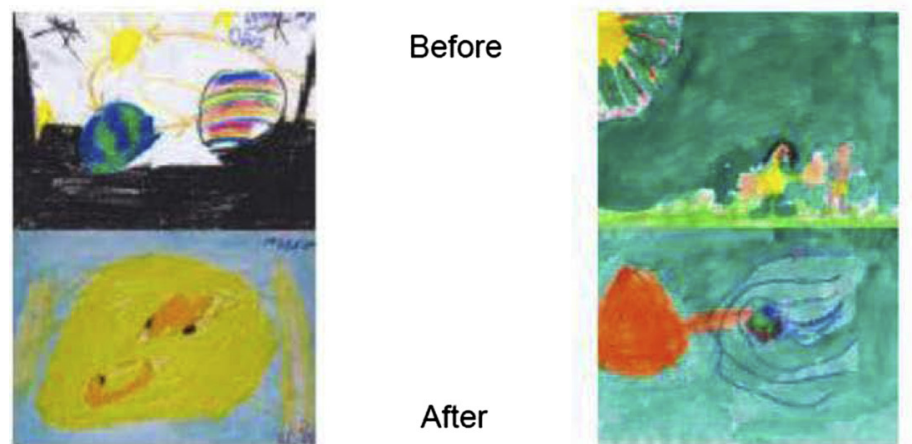

Before

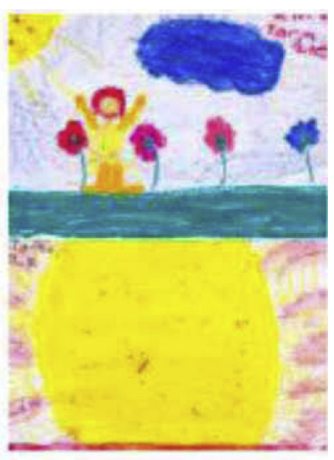

Before

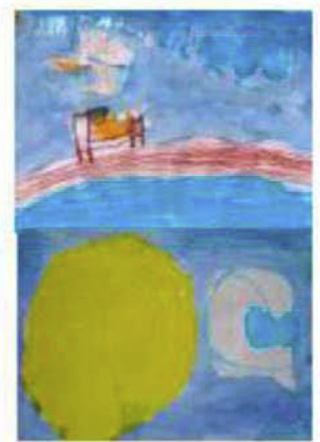

Fig. 3. Some of the typical drawings of the Turkish children from the Başkent University Özel Ayşeabla" private school in Ankara (I Love My Sun 3: 1st visit).

the nature of the Sun and Earth, as well as the interaction - processes occurring - between the two entities. To better compare results from different school visits, "I Love My Sun" events became "standardised" during the "I Love My Sun 3" phase by producing an "I Love My Sun" power-point presentation template with accompanying text built on the presentations that had been given [6]. The contents of the lecture have been prepared in a way (and level) to spark interest in natural phenomena such as the Sun. To better popularise space weather, effects of space weather such as the northern lights are given. It is encouraged that the lecture be given in a friendly manner, meaning, that it is to be given interactively encouraging the children to ask questions.

\section{Examples from Events}

\subsection{Love My Sun 2 Event}

In the "I Love My Sun 2" phase it was investigated whether this initiative could provide an innovative approach to teaching children with ASD. One school was visited and a comparison between children with and without ASD attending the same lecture is presented here.

\subsection{1. “Kütükçü Alibey Primary School”, Turkey (2nd November 2009)}

As part of the Ankara Ministry of Education training programme, the Kütükçü Alibey Ilköğretim Okulu Primary State School hosts children with ASD. In this school individual training $(2 \mathrm{~h} /$ day $)$, group therapy $(2 \mathrm{~h} /$ day $)$ and training together with children without ASD ( $2 \mathrm{~h}$ /day) comprise the daily schedule for the children with ASD. For more information on ASD see Frith (2004) and Fombonne (2005).
The "I Love My Sun" event was performed with both groups of students (with and without ASD) in the same art class (same lecture was given to both groups of children). Coloured crayons were provided by the lecturer. The major characteristics of children with ASD who participated in this event are summarised below:

- They did not have mental retardation or had only a mild level of retardation.

- They were all high functioning (capable of useful speech for mutual communication); they were able to attend some activities with children without ASD.

- They had better communication than expression; it was possible to conduct the "I Love My Sun" event as if there were only children without ASD participating.

- They all had sufficient receptive language to carry out the task; they could listen, understand and absorb the information conveyed to them by using ordinary language.

- There was sufficient eye contact to follow and comprehend the instructions.

- Their attention span was of sufficient duration so they were not distracted.

- They did not have frequent stereotype involuntary movements that interfered with their attention.

Figure 1 illustrates typical results of "before" and "after" drawings made by children without ASD, while Figure 2 presents typical results of children with ASD. Even though, statistically the samples are not in a large quantity (six children with ASD and six without), the typical characteristics of autism are detected within the context of space weather. For example, the students with ASD paid attention to the details rather than the global picture (global processing vs. local processing) and they exhibited perseveration (persisted on drawing their impressions). It was found that these children displayed an unusual 


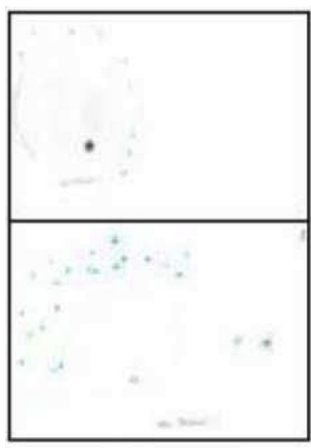

Before

After

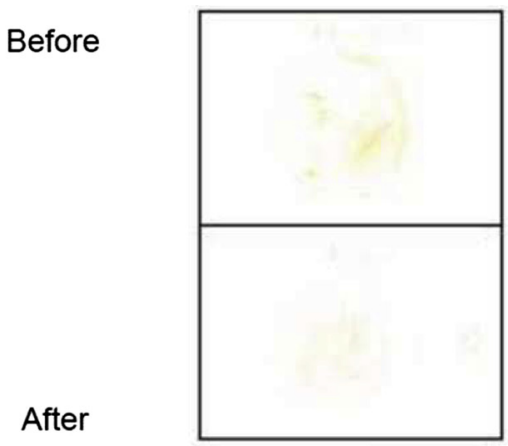

Before
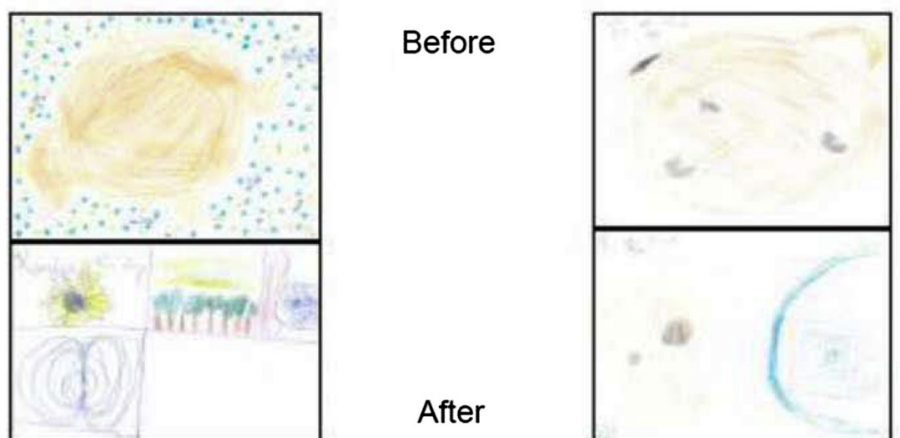

Before

After

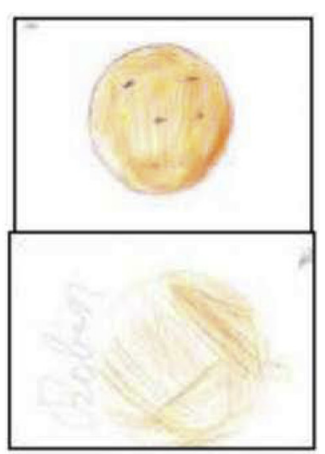

Before

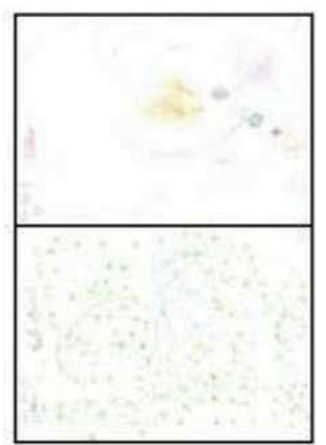

Fig. 4. Some of the typical drawings of the Belgian children performed at the public observatory Urania in Antwerp (I Love My Sun 3).

creativeness that nobody would have imagined. See, for example, the top left "after" "Picasso-like" drawing in Figure 2. Furthermore, the bottom right "before" and "after" drawings in Figure 2 are by a student who normally refused to use coloured crayons until this event; being very stubborn (perseveration) is a characteristic of ASD (Korkmaz 2000).

\subsection{Love My Sun 3 Events}

In the "I Love My Sun 3" phase a spatial dimension was added, meaning that more than one country participated in the initiative. The main impressions and results from four countries are given in the following four sub-sections in chronological order.

\subsubsection{B̈̈ Özel Ayşeabla School, Turkey (22nd March 2010)}

School children from the "Başkent University Özel Ayşeabla" private school in Ankara, Turkey participated in the first "I Love My Sun 3" event on 22 March 2010. Three classes, consisting of 66 children (8-10 years old), participated. In this school the children were already in possession of coloured crayons. Some of the short-listed "before" and "after" drawings are presented in Figure 3.

Almost all children expressed the Sun in their drawings as a "picture story", specifically in the "before" drawings since, as interpreted by the art pedagogue, children tended to place important objects (humans, animals, nature) in hierarchical order in their drawings (favorite objects were placed at central locations and drawn on larger scales). Most of the children put the quarter of the Sun at either the top-left or right-hand corner of their "before" drawing, and is a very normal way of how children perceive the location of the Sun.

Almost all of the children absorbed the information conveyed to them concerning the Sun (e.g., sunspots, flares,
Sun-Earth relations). The Sun became the dominant motif in the "after" drawings which indicates that the children perceive the Sun as an independent object/identity. This result suggests that the main message of the lecture came across well - the Sun has a very important role in our daily existence - and was emphasised in the "after" drawings.

\subsubsection{Public Observatory Urania, Belgium (2nd October 2010)}

During the school year the public observatory Urania organises once a month on Saturday afternoons two courses for young star enthusiasts: Sterrenstofjes (which means "stardust" in Dutch) for children (7-9 years old) and Sterrenplukkers ("star harvesters" in Dutch) for children (10-11 years old). During the school holidays, young star enthusiasts are also able to attend 1-week "Kids Astro Camps", where they learn about stars, planets, Sun, etc. In the week they also go to a planetarium to learn about the constellations and they have the opportunity to look through a telescope at the Moon or a planet.

In total 47 pairs of drawings were collected during the Urania "I Love My Sun 3" event. The youngest participant was 6 years old, the oldest 12 years old, with the mean age being 8.9 years. Some of the short-listed "before" and "after" drawings are presented in Figure 4.

The results obtained from this event show that almost all of the children absorbed the information conveyed to them concerning the Sun (e.g., sunspots, flares, Sun-Earth relations). After the lecture, a significant number of children focused on the relationship between the Sun and the Earth (e.g., drew the geomagnetic field and the interaction of solar particles with it). Furthermore, after the talk, a significant number of children expressed the difference in scale between the Sun and the Earth. This is a very important observation: the Sun is the largest object in the Solar System, both in terms of size and mass. The Sun was a very dominant factor in both the "before" 

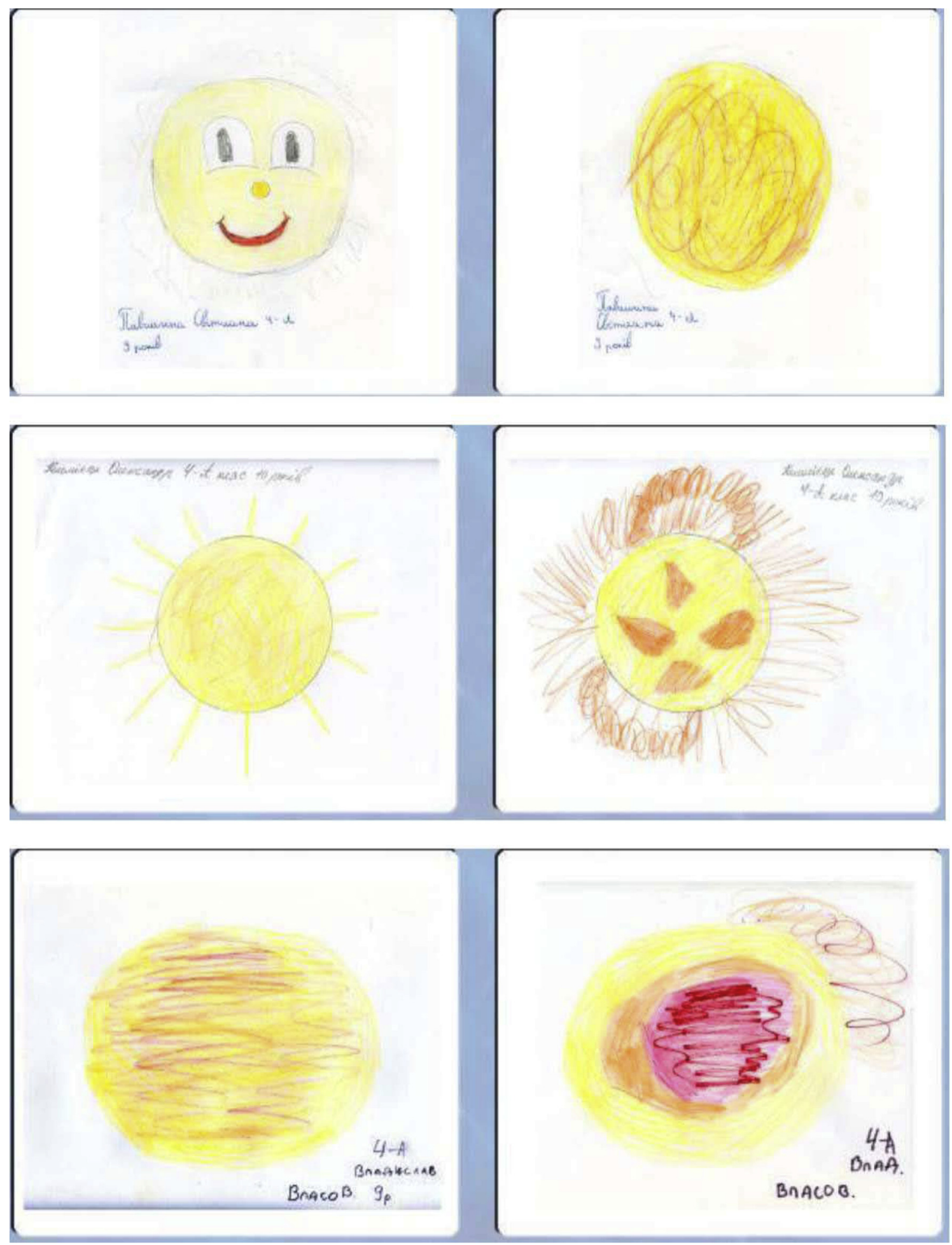

Fig. 5. Some of the typical drawings of the Ukrainian children from the public school No. 286 in Kyiv (I Love My Sun 3).

and "after" drawings. Probably the reason for this is that the children at the Urania Observatory already had prior knowledge on the topic and a specific interest in astronomy.

\subsubsection{Public school No. 286, Ukraine (7th April 2011)}

The school that was visited is located on the outskirts of Kyiv (population of $\sim 3.5$ million) in a highly educated area (many families have scientific or technical background). In contrast to the two previous described events, a lecture was given to 6 elementary classes (6-10 years old) at once - about 180 children in total.

Examples of the short-listed "before" and "after" drawings are presented in Figure 5. Concerning the "before" drawings, they mostly look like an orange circle, sometimes with rays; less than half of them feature eyes and mouth on the Sun, maybe due to the fact that most children are from educated families. Boys tend to represent the Sun more schematically, 


\section{"Lazar Savatic" school}
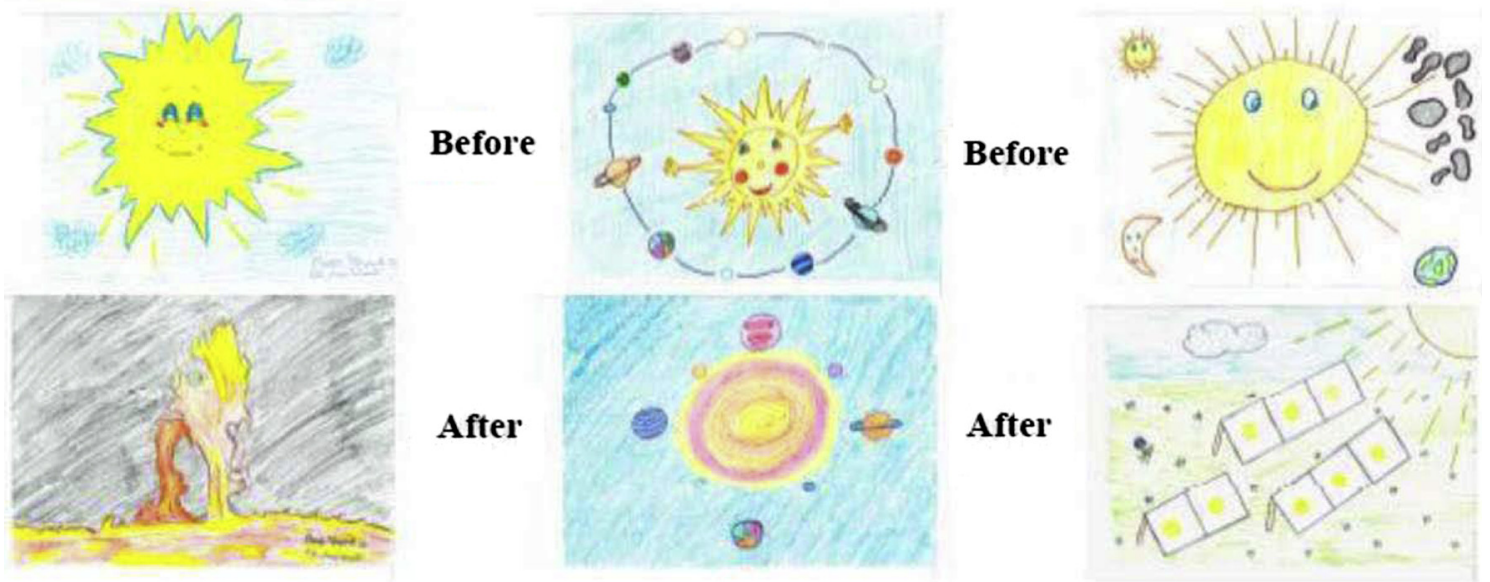

The "Bratstvo" school
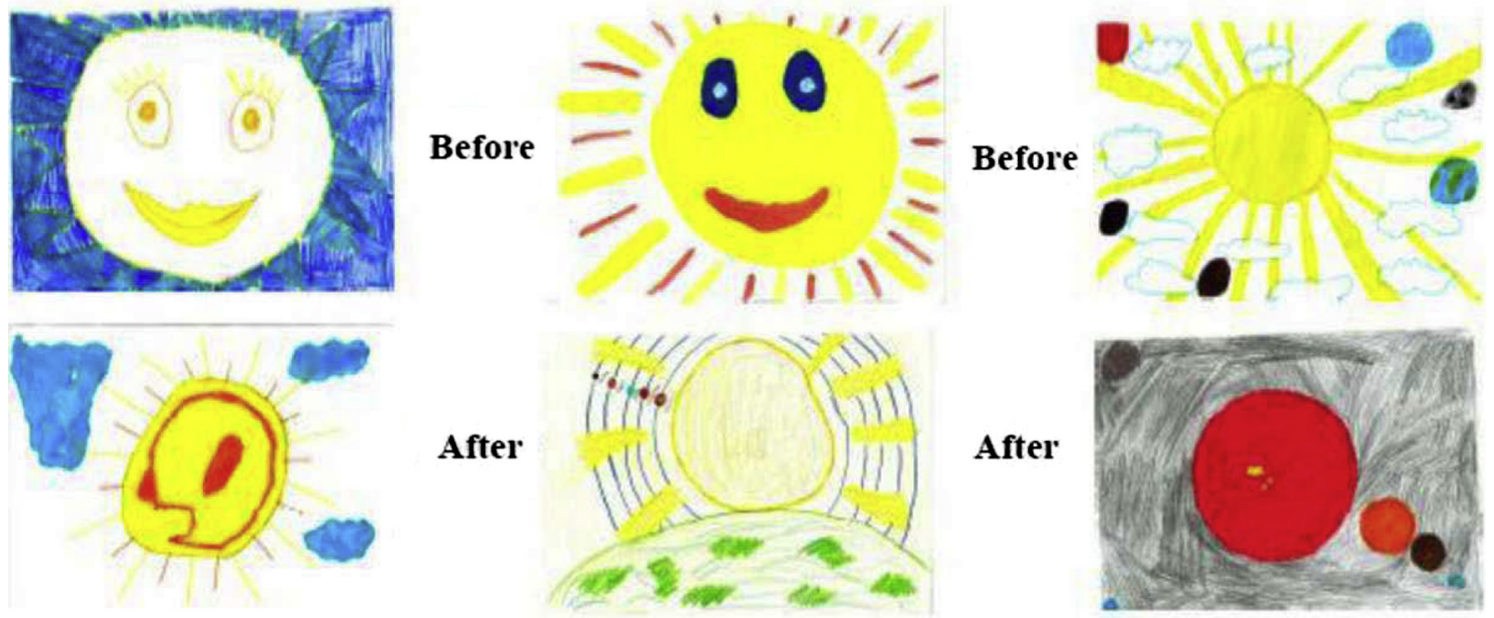

Fig. 6. Some of the typical drawings of the Serbian children from the Lazar Savatic school in Zemun and the Bratstvo school in Aradac (I Love My Sun 3).

whereas the eyes and mouth appear more often in girls' drawings (10 vs. 7 cases). As expected, most "after" drawings feature sunspots, prominences, etc.

Most children understood the lecture very well. In particular, they had no problem understanding the concept of magnetic fields and their interaction, which is very interesting since they had not studied physics yet. No significant dependence on student age was found. All classes were roughly on the same level, with the exception of one especially successful class (they might have been already aware of basic solar physics).

\subsubsection{Two Serbian Schools: Lazar Savatic and Bratstvo Schools (6th June 2011; 9th September 2011)}

\subsubsection{Lazar Savatic" school in Zemun}

The "Lazar Savatic" school in Zemun is one of the best schools in the City of Belgrade. There were 38 students (11 years old) from two classes who attended the first lecture. This was followed by two other classes (35 students total) who attended the next lecture. The children were very familiar with PCs and the Internet. During discussions they were very active and asked some relevant scientific questions.

\subsubsection{Bratstvo school in village Aradac}

The "Bratstvo" school is located in a small village Aradac in the Zrenjanin municipality which is ethnically mixed.
The event was attended by 35 children in the fourth grade class (10-11 years old). These children did not have such a good general education and were not familiar with PCs and the Internet.

Some short-listed "before" and "after" drawings from both schools are presented in Figure 6. A large number of the "before" lecture drawings were found to be typical for children (10-11 years old); the Sun was often drawn as is usual for children. Around $30 \%$ of the "after" lecture drawings were done in a different manner showing the knowledge that was obtained during the lecture; this specifically concerned children whose "before" lecture drawings had been done very well.

These two events showed that children $(10-11$ years old $)$ are educated enough to follow a lecture and ready to acquire new knowledge. They are familiar with terms and concepts such as temperature, gravitational force, magnets, light, ultraviolet radiation and problems with skin after exposure to the Sun. They also have knowledge from mathematics to calculate up to million and understand the meaning of $1 / 100$.

\subsection{Love My Sun 4 Event}

In the "I Love My Sun 4" phase a "temporal" dimension was added and a school where the event had been held earlier was re-visited. 


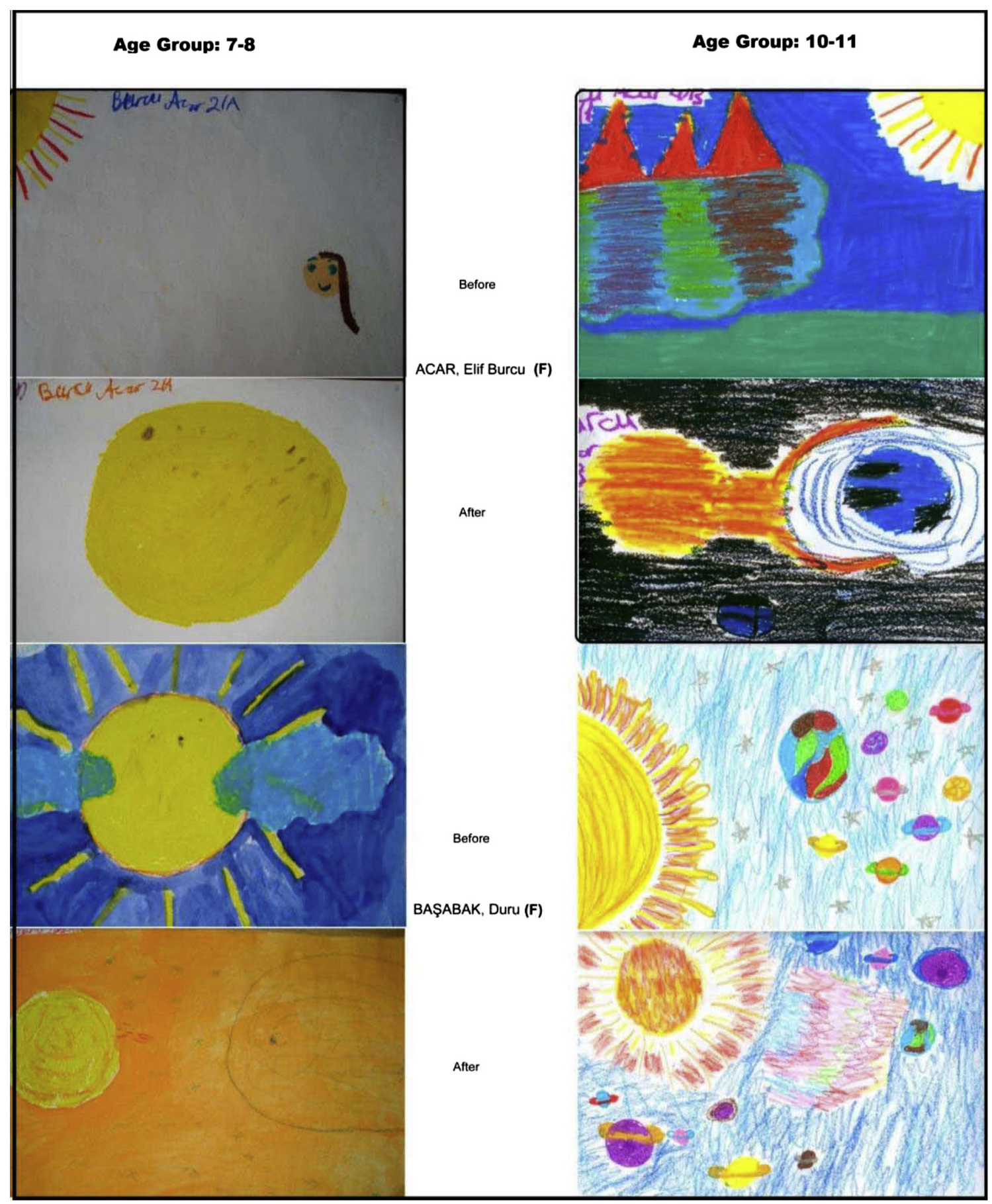

Fig. 7. Some of the typical drawings of the Turkish children from the Başkent University Özel Ayşeabla" private school in Ankara with temporal dimension (left-hand drawings: 1st visit, right-hand drawings: 2nd visit). (I Love My Sun 4: 2nd visit).

\subsubsection{B̈̈ Özel Ayşeabla School, Turkey (18th October 2011)}

The BÜ Özel Ayşeabla school children of the previous "I Love My Sun 3" Event (Sect. 3.2.1) were re-visited. The level of information that had been "digested" a year ago was investigated by performing the "I Love My Sun" event again on a subset of 10 students who were now 10 or 11 years old. Some of the short-listed "before" and "after" drawings of the two BÜ Özel Ayşeabla school visits are presented in Figure 7 (left-hand drawings: 1st visit, right-hand drawings: 2nd visit).

The outcome of the "I Love My Sun 4" event has been evaluated by using a "metric-like" template". Table 1 presents the metric template used for the relative comparison of the two BÜ Özel Ayşeabla school visits of the "before" (B) and "after" (A) drawings from the second visit. Results obtained from this event by using the metric are presented in Table 2. For example, Bi concerns the evaluation if "human features are used as solar features" in the "before" drawings (Table 1); for each of the ten students listed in Table 2 the answer was "no". It is shown that the objective of creating an awareness of the scientific issues regarding the Sun, Sun-Earth relations was fulfilled again. However, within this group (10-11 years old) the differences between the "before" and "after" drawings are not as pronounced as the differences observed when the children were $7-8$ years old. 
Table 2. Relative comparison of the two BÜ Özel Ayşeabla school vists for a subset of students; $B=$ before, $A=$ after, and $i=$ item number defined in Table 1.

\begin{tabular}{|c|c|c|c|c|c|c|c|c|c|c|c|}
\hline $\begin{array}{l}\text { Student } \\
\text { number }\end{array}$ & Gender & $\mathrm{Bi}$ & Bii & Biii & Biv & $\mathrm{Ai}$ & Aii & Aiii & Aiv & $\mathrm{Av}$ & Avi \\
\hline 1 & $\mathrm{~F}$ & No & Yes & No & + & Flare & $\begin{array}{l}\text { Space weather } \\
\text { magnetosphere }\end{array}$ & Yes & Yes & No & + \\
\hline 2 & $\mathrm{~F}$ & No & Yes & Yes & + & Other & Other & Yes & Yes & No & + \\
\hline 3 & $\mathrm{~F}$ & No & Yes & No & + & Other & Other & Yes & Yes & No & ++ \\
\hline 4 & $\mathrm{~F}$ & No & Yes & Yes & ++ & $\begin{array}{l}\text { Sun spot } \\
\text { flare }\end{array}$ & $\begin{array}{l}\text { Space weather } \\
\text { magnetosphere }\end{array}$ & Yes & Yes & No & ++ \\
\hline 5 & $\mathrm{~F}$ & No & Yes & Yes & + & Other & Other & Yes & Yes & No & ++ \\
\hline 6 & M & No & Yes & No & $\begin{array}{l}0 \text { (N } \\
\text { Diff.) }\end{array}$ & & $\begin{array}{l}\text { Space weather } \\
\text { magnetosphere }\end{array}$ & Yes & Yes & No & ++ \\
\hline 7 & M & No & Yes & No & + & Other & Space Weather & Yes & Yes & No & ++ \\
\hline 8 & M & No & Yes & No & $\begin{array}{l}0 \text { (N } \\
\text { Diff.) }\end{array}$ & Other & Other & Yes & Yes & No & - \\
\hline 9 & M & No & Yes & No & + & Other & Magnetosphere & Yes & $\begin{array}{l}\text { No } \\
\text { Diff. }\end{array}$ & No & - \\
\hline 10 & $\mathrm{M}$ & No & Yes & Yes & + & Other & Space weather & Yes & Yes & No & + \\
\hline
\end{tabular}

This event suggests that "I Love My Sun" is more influential and effective in creating awareness among younger children (7-8 years old) compared to those of the 10-11-year age group. It was observed that during the year since the first visit and the current visit the children had added to their perception a considerable amount of information via popular, commercial nonscientific media.

\section{Conclusion}

To create awareness and interest concerning space weather, the "I Love My Sun" initiative, an interdisciplinary educational tool, has been developed for school children including children with ASD. This paper has presented the four phases of "I Love My Sun" initiative by describing their associated "I Love My Sun" events. In general, the drawings that the children drew in all cases reflected their experience of participating in an "I Love My Sun" event. Their conception of the Sun and Sun-Earth relations changed in each of the individual cases. It should be noted that the exercise has been aimed to demonstrate the "method" rather than producing "statistical results". The "method" can be justified statistically when the number of "I Love My Sun" events has increased to a significant number of events.

COST ES0803 Action "I Love My Sun" events have been presented at the annual European Space Weather Week (ESWW) meetings (ESWW6, ESWW7 and ESWW8), as well as at all of the Management Committee meetings of the COST ES0803 Action. In parallel, the activity has been presented at the ESA Space Weather Working Team (SWWT) Plenary meetings. been:

The main outcomes of the "I Love My Sun" initiative have

- In "I Love My Sun 2" a new approach in teaching was investigated by including children with ASD; To our knowledge this is the first time such an educational tool has been used to teach children with ASD together with children without ASD. These first results of the "I Love My Sun" as an educational tool for children with ASD are promising.

- One of the main objectives of the "I love My Sun" initiative, in the framework of the COST ES0803 Action, was to conduct the Project at European level. Therefore, in "I Love My Sun 3" a "spatial parameter" was introduced and "I Love My Sun" events were conducted in Turkey, Belgium, Ukraine and Serbia.

- In "I Love Sun 4", a "temporal dimension" (same class was re-visited a year later) and a "metrics", which also are two novel components, were brought into the Project.

- Although, sample sizes are small, it may be tentatively concluded that the impact of the training (lecture given) is positive in case of the girls (8-10 years old) with respect to that of the boys.

- No matter how elementary the level of information, it is important that children are exposed to topics such as the Sun and related phenomena while they are still young.

- "I Love My Sun" events have become "standardised" an "I Love My Sun" power-point presentation template with accompanying text was produced built on the presentations that had been given in "I Love My Sun 3".

The novel method employed in the "I Love My Sun" initiative was developed for performing education and outreach activities as a way of introducing this topic to non-professionals in an enjoyable and relaxing environment. A novel metric-like template was developed to quantify the non-measurable outcomes of an education activity in a manner as objective as possible. The method and the technique used for measuring the outcomes are adoptable and open to further developments and generalisations. Therefore, the method and metric developed are not limited to "I Love My Sun", but can be applied to other activities. It is expected that this work will be able to serve as a means of setting education and outreach standards for assessing the amount of information that children (7-11 years old) acquire when being taught space science.

The authors of this paper will continue to conduct "I Love My Sun " events and at the same time introduce other scientists to this international initiative. In parallel, one of the goals will be to provide training for teachers so that in the long run they themselves can utilise this tool without the presence of a scientist. More specific plans for the individual countries include:

- In Turkey the "I Love My Sun" tool will be enhanced in terms of target population and novel methods employed by the Turkish group.

- It is proposed by the Turkish group that events including children with and without ASD be held in the future for comparison with the results from "I Love My Sun 2". 
- In Belgium “I Love My Sun” events will be held during dedicated science days where the public is invited to participate.

- In Ukraine, the "I love my Sun" programme is planned to continue in close collaboration with the Astronomical school hosted by Planetarium Kyiv to optimise the lectures with respect to educational impact. Afterwards, it is planned to use the gained experience to develop a set of materials for extracurricular activities in public schools to dramatically increase the coverage of the programme.

- In Serbia, schools in small villages will be targeted in the future. This is because children in such schools are very interested in acquiring new knowledge, but they are not often in the position to acquire it from their parents. Maybe the best period for performing these events is during spring. After a long and cold winter, children spend more time outside enjoying the good spring weather. Also it is a period when, most of the school year, is finished.

- Future aims of the "I Love My Sun" initiative are to include more countries from all over the world.

Acknowledgements. It is acknowledged and the authors thank all the children who took part in the "I Love My Sun 2, 3 and 4" events, as well as the following people for their vital support during these events and for poster preparations for meetings:

- Dr. Mustafa Kuzu, Professor and Vice Rector, Başkent Univ. (BÜ).

- Mr. Kazım Özcan, Principal, Küçükçü Ali Bey Primary School, Ankara, Turkey.

- Ms. Hilal Türker, Headmaster, BÜ, Ankara.

- Ms.Sevgin Kurtuluş, Headmaster, BÜ, Özel Ayşeabla School, Ankara.

- Ms. Muteber Gönüllü, Art Teacher, BÜ, Özel Ayşeabla School, Ankara.

- TA. Batu Demir, TA. Berk Korkut, Mr. A. Samet Yüzlü, Mr Navid Ronaghi, Department of Aerospace Engineering, ODTÜ/METU, Ankara.

- Mr. Yves Geunes, Belgian Institute for Space Aeronomy, Brussels (built and maintains the "I Love My Sun" website).

- Nora Geunes, Angelina Schoep, "Campus de Wingerd", Overpelt (drew the "I Love My Sun" graphics and logo), Brussels.

The authors of this paper who constitute the "I Love My Sun" Team also greatly acknowledge the following people who have contributed significantly to the success of the "I Love My Sun" initiative:

- Dr. Barış Korkmaz, Professor of Neurology, İstanbul Univ. Cerrahpaşa Faculty of Medicine, İstanbul, Turkey (specialist on autism with spectrum disorder).

- Dr. Zafer Gençaydın, Professor, Hacettepe University, Ankara, Turkey (Artist, Art Pedagogue, Advisor on Drawings of Children).

- Cengiz Özan, Advisor, Kütükçü Ali Bey Primary School, Ankara, Turkey (Network Administrator).
- Gönül Arslantaş; Leylifer Konakul, Art Teachers, Kütükçü Ali Bey Primary School, Ankara, Turkey.

- Hüsniye Akkuş; Saniye Aykut; Yeşim Parlak, Class Teachers, Kütükçü Ali Bey Primary School, Ankara, Turkey.

- Doç. Dr. Güler Küçükturan, Director, Başkent Üniversitesi (BÜ) Özel Ayşeabla Schools, Ankara, Turkey.

- Hilal Erdinç, Director, Advisor, BÜ Özel Ayşeabla Schools, Ankara, Turkey.

- Dr. Aytül Şekercioğlu, Art Teacher, BÜ Özel Ayşeabla Schools, Ankara, Turkey.

- Ayça Kara - 2D; Gülay Gögüüş - 2A; İncilay Erensayın 2C; Müjgan Coşkun - 2B, Class Teachers, BÜ Özel Ayşeabla Schools, Ankara, Turkey.

- Dr. Aytül Şekercioğlu, Art Teacher, BÜ Özel Ayşeabla Schools, Ankara, Turkey.

\section{References}

Adams, J., and T. Slater, Astronomy in the National Science Education Standards, J. Geosci. Edu., 48 (1), 39-45, 2000.

Fombonne, E., Epidemiology of autistic disorder and other pervasive developmental disorders, J. Clin. Psych., 66 (Suppl. 10), 3-8, 2005.

Frith, U., Emanuel Miller lecture: confusions and controversies about Asperger syndrome, J. Child Psychol. Psych., 45, 672-686, 2004.

Korkmaz, B., Pediatrik Davranış Nörolojisi, (Pediatric Behavioral Neurology). İ.Ü. yayınları yayın no:4267 Cerrahpaşa Tip fakültesi yayın no:230, İstanbul, 2000.

Meyer, A.O., M.J. Mon, and S.T. Hibbard, The lunar phases project: a mental model-based observational project for undergraduate nonscience majors, Astron. Edu. Rev., 10 (1), http://aer.aas.org/ resource/1/aerscz/v10/i1/p010203s1, 2011.

Rollins, M.M., J.J. Dentton, and D.L. Janke, Attainment of selected earth science concepts by Texas high school seniors, J. Edu. Res., 77 (2), 81-88, 1983.

Thompson, B.J., N. Gopalswamy, J.M. Davila, and H.J. Haubold (Eds.), Putting the "I" in IHY, XV, 371 pp., 2009.

Tulunay, Y., Space weather and Europe - an educational tool with the Sun (SWEETS), Final Report, http://cordis.europa.eu/ documents/documentlibrary/126792761EN6.pdf, 2008.

Tulunay, Y., J., Lilensten, A. Belehaki, M. Messerotti, R. Vainio, J. Watermann, and S. Poedts, Education: discussion and case studies, in COST 724 Final Report: Developing the Scientific Basis for Monitoring, Modeling and Predicting Space Weather, 395-399, http://www.cost.esf.org/library/publications/09-04-Developingthe-Scientific-Basis-for-Monitoring-Modelling-and-PredictingSpace-Weather, 2009.

Yair, Y., R. Mintz, and S. Litvak, 3D-virtual reality in science education: an implication for astronomy teaching, J. Comput. Math. Sci. Teach., 20 (3), 293-305, 2001.

[1] http://mms.gsfc.nasa.gov/education.html

[2] http://www.unawe.org/

[3] http://ihy2007.org/

[4] http://www.cost.esf.org/domains_actions/essem/Actions/Modelling and Predicting_Space_Weather

[5] http://www.costes0803.noa.gr

[6] http://www.ilovemysun.org/

Cite this article as: Tulunay Y, Bock Crosby N, Tulunay E, Calders S, Parnowski A \& Sulic D: The COST example for outreach to the general public: I love my Sun. J. Space Weather Space Clim., 2013, 3, A04. 